\title{
Palliative and corrective surgery in low-weight infants is associated with an increased mortality risk: How can we do better?
}

\author{
Petros V. Anagnostopoulos, MD
}

See related article on pages 2508-14.

In this issue of the Journal of Thoracic and Cardiovascular Surgery, Alsoufi and colleagues ${ }^{1}$ from Emory University examine the effect of low patient weight $(<2.5 \mathrm{~kg})$ on contemporary surgical results and provide new information on the long-term outcomes in this challenging group of patients.

Although the low-weight study group and the normalweight comparison group had similar proportion of uniand biventricular patients, low-weight patients had a higher incidence of extracardiac anomalies, prematurity and STAT (Society of Thoracic Surgeons-European Association for Cardio-Thoracic Surgery) category 4 and 5 lesions. Lowerweight patients had a higher incidence of palliation and lower use of cardiopulmonary bypass (CPB). Postoperative ventilation, length of stay in the intensive care unit (ICU) and overall hospital length of stay were higher in the low-weight patients. The effect of low weight persisted even in patients with low STAT categories when adjusting for prematurity, extracardiac anomalies, and palliation versus repair. The main message of this article is clear: low weight continues to be a significant risk factor associated with mortality and increased resource utilization after neonatal cardiac surgery and this risk persists for at least 1 year after the operation.

This is not the first time that the adverse effect of low weight has been identified in single center and registry analyses. ${ }^{2-5}$ Advances in perioperative care, surgical technique, and perfusion have not been translated into improved outcomes in low-weight patients. How can we do better?

Is this a problem of inadequate technical performance? Are these repairs leaving patients with more residual lesions and are CPB times longer to accomplish a good surgical repair? In the current series, there is no difference in the technical results of the operations. Although some of the specific data are not available, the reoperation rate for residual lesions

\footnotetext{
From the Division of Pediatric Cardiothoracic Surgery, The American Family Children's Hospital, University of Wisconsin School of Medicine and Public Health, Madison, Wis

Disclosures: Author has nothing to disclose with regard to commercial support.

Received for publication Sept 23, 2014; accepted for publication Sept 26, 2014; available ahead of print Oct 23, 2014.

Address for reprints: Petros V. Anagnostopoulos, MD, The American Family Children's Hospital, University of Wisconsin School of Medicine and Public Health, H4/358 Clinical Sciences Clinical Sciences Center, 600 Highland Ave, Madison, WI 53792 (E-mail: petros@surgery.wisc.edu).

J Thorac Cardiovasc Surg 2014;148:2515-6

$0022-5223 / \$ 36.00$

Copyright (c) 2014 by The American Association for Thoracic Surgery

http://dx.doi.org/10.1016/j.jtcvs.2014.09.113
}

was similar in the 2 groups as were the incidence of return to bypass and CPB time. A recent study from New York provides further support that the reason for the higher mortality is not lack of ability to "get the repair right the first time." ${ }^{4}$ In the Atlanta series, the mortality in the low-birth-weight infants was higher even in patients with the less technically complicated STAT 1 to 3 operation categories.

The question of complete repair versus palliation in the patients in whom complete repair is possible has also been studied in the past. Low weight has been associated with increased mortality after aortopulmonary shunts. ${ }^{6}$ Patients with pulmonary atresia and ventricular septal defect generally do better with complete repair and patients with tetralogy of Fallot seem to have similar results after repair or palliation. ${ }^{2,7}$ The question of whether the neurodevelopmental outcomes differ in patients with palliation or repair remains unanswered.

The timing of the surgery has also been examined. Should we operate immediately or wait for maturation and weight gain, something that is frequently difficult to achieve and may expose the patient to unnecessary risks? The Toronto group reported that the outcomes in verylow-weight infants $(<2.0 \mathrm{~kg})$ who received usual and delayed intervention were similar. ${ }^{5}$ Events that influence the timing and outcome of surgery (intracranial hemorrhage, necrotizing enterocolitis, or pulmonary complications associated with prematurity) in these small babies can be difficult to identify and analyze in a retrospective study.

Many believe that the increased mortality risk is simply associated with the patient's premature status and the associated comorbidities. Are these patients being cared for in the right environment? One of the clearest success stories over the last 2 decades has been the development of the pediatric cardiac ICU. Trained, double-boarded cardiology and ICU subspecialists have cared successfully for the sickest neonates and children after surgical palliation and repair However, neonatology specialists are not always available in many pediatric cardiac ICUs. Is this one of the reasons for our lack of progress? A recent report from one of the programs in the country that care for neonates in a specialized cardiac neonatal ICU showed that mortality remains high at $10.9 \%$. On the other hand, mortality in lowweight patients after the Norwood operation was only $8 \%$, much lower than reported in other series. ${ }^{4}$ Is the New York group showing us the way?

The article by Alsoufi and colleagues ${ }^{1}$ is important because it once again demonstrates that there is room for improvement in our care of low-weight patients. A major 
weakness of our collective approach to the study of this problem is that we have not become granular enough. Univentricular patients are retrospectively studied together with biventricular patients. Comorbidities and the timing of surgery are difficult to distil. The role of the neonatal cardiac ICU is challenging to evaluate. We must study each of these factors separately and prospectively in a multiinstitutional way. Our past is filled with examples of success in tackling problems that were once believed impossible. It is time to apply the lessons of the past to improve the outcomes in this very difficult group of patients.

\section{References}

1. Alsoufi B, Manlhiot C, Mahle WT, Kogon B, Border W, Cuadrado A, et al. Lowweight infants are at increased mortality risk after palliative or corrective cardiac surgery. J Thorac Cardiovasc Surg. 2014;148:2508-14.
2. Curzon CL, Milford-Beland S, Li JS, O’Brien SM, Jacobs JP, Jacobs ML, et al. Cardiac surgery in infants with low birth weight is associated with increased mortality: analysis of the Society of Thoracic Surgeons Congenital Heart Database. J Thorac Cardiovasc Surg. 2008;135:546-51.

3. Reddy VM, McElhinney DB, Sagrado T, Parry AJ, Teitel DF, Hanley FL. Results of 102 cases of complete repair of congenital heart defects in patients weighing 700 to 2500 grams. J Thorac Cardiovasc Surg. 1999;117:324-31.

4. Kalfa D, Krishnamurthy G, Duchon J, Najjar M, Levasseur S, Chai P, et al. Outcomes of cardiac surgery in patients weighing less than $2.5 \mathrm{~kg}$ : Effect of patient-dependent and -independent variables. J Thorac Cardiovasc Surg. 2014; 148:2499-506.

5. Hickey EJ, Nosikova Y, Zhang H, Caldarone CA, Benson L, Redington A, et al. Very low-birth-weight infants with congenital cardiac lesions: is there merit in delaying intervention to permit growth and maturation? J Thorac Cardiovasc Surg. 2012;143:126-36, 36.e1.

6. Petrucci O, O’Brien SM, Jacobs ML, Jacobs JP, Manning PB, Eghtesady P. Risk factors for mortality and morbidity after the neonatal Blalock-Taussig shunt procedure. Ann Thorac Surg. 2011;92:642-51; discussion 651-2.

7. Azakie A, Johnson NC, Anagnostopoulos PV, Egrie GD, Lavrsen MJ, Sapru A. Cardiac surgery in low birth weight infants: current outcomes. Interact Cardiovasc Thorac Surg. 2011;12:409-13; discussion 414. 